\title{
Programmes for the prevention of mother- to-child HIV infection transmission have made progress in Yunnan Province, China, from 2006 to 2015: a cost effective and cost-benefit evaluation
}

\author{
Xiaowen Wang ${ }^{1,2}$, Guangping Guo ${ }^{3}$, Jiarui Zheng ${ }^{3}$ and Lin $\mathrm{Lu}^{2,4^{*}}$
}

\begin{abstract}
Background: Prevention of mother-to-child transmission (PMTCT) of HIV programmes have substantially reduced HIV infections among infants in Yunnan Province, China. We conducted a macro-level economic evaluation of Yunnan's PMTCT programmes over the 10 years from 2006 to 2015 from a policymaker perspective.

Methods: The study methodology was in accordance with the guidelines from the Consolidated Health Economic Evaluation Reporting Standards (CHEERS) statement. We quantified the output from the Yunnan's PMTCT programmes by estimating the number of paediatric HIV infections averted and the relative savings to both the health care system and society. The return-on-investment ratio (ROI) was calculated as the output (numerator) divided by the input (denominator).

Results: We have found that the US\$ 49 million investment in Yunnan's PMTCT programmes over the period from 2006 to 2015 averted an estimated 2725 new paediatric HIV infections and resulted in an estimated 134,008 QALY acquired. It saved an estimated US\$ 0.5 billion in treatment expenditures for Yunnan's healthcare system and nearly US\$ 3.9 billion in productivity. The ROI was 88.4, meaning every US\$ 1 invested brought about US\$ 88.4 in benefits.

Conclusions: Our results support the ongoing investment in PMTCT programmes in Yunnan Province. The PMTCT strategy is a cost effective and cost-benefit strategy in the periods from 2006 to 2015. Despite higher investments in the future, the overall investment in the PMTCT programmes in Yunnan province could be offset by averting more paediatric infections.
\end{abstract}

Keywords: Prevention mother-to-child transmission of HIV, Economic evaluation, Cost effective, Cost benefit, Yunnan Province

\section{Background}

Prevention of mother-to-child transmission (PMTCT) of HIV infection became a key public health priority in China in 2002 [1]. In the fifteen years since 2002, China's HIV PMTCT programmes have played an important

\footnotetext{
*Correspondence: lulin62_wjw@163.com; lulin@yncdc.cn

${ }^{2}$ Department of Public Health, Kunming Medical University, No. 1168, West

Chunrong Road, Yuhua Street, Chenggong District, Kunming 650599, Yunnan Province, China

${ }^{4}$ Health and Family Planning Commission of Yunnan Province, No. 309, Guomao Street, Kunming 650299, Yunnan Province, China

Full list of author information is available at the end of the article
}

role in the prevention of HIV infection nationwide. A meta-analysis has shown that the mother-to-child transmission (MTCT) rate in China declined from 12.90 to $2.29 \%$ from 2004 to 2010 , demonstrating a decrease year-by-year under the PMTCT strategies [2]. In 2017, China began working towards an official certification for the elimination of HIV transmission from motherto-child via the World Health Organization.

In southwest China's Yunnan province, the number of people living with HIV and AIDS was estimated to be 93,437 at the end of 2016 [3] (total population of

(c) The Author(s). 2019 Open Access This article is distributed under the terms of the Creative Commons Attribution 4.0 International License (http://creativecommons.org/licenses/by/4.0/), which permits unrestricted use, distribution, and reproduction in any medium, provided you give appropriate credit to the original author(s) and the source, provide a link to the Creative Commons license, and indicate if changes were made. The Creative Commons Public Domain Dedication waiver (http://creativecommons.org/publicdomain/zero/1.0/) applies to the data made available in this article, unless otherwise stated. 
4.7 million in Yunnan Province in 2016 [4]), the highest among all provinces and municipalities. PMTCT programmes have been carried out since 2003 in Yunnan Province. With more than one decade of development and efforts, these programmes have been shown to be successful. Previous studies conducted by various cities and counties in Yunnan province have shown that the coverage rate of PMTCT programmes is nearly $100 \%$ in their own areas [5-14]. Based on report data from Yunnan Provincial Maternal and Infant Health Care Centre, the MTCT rate declined from $34.80 \%$ in 2003 to $3.13 \%$ in 2015 throughout the province.

However, although the clinical and public health benefits of Yunnan's PMTCT programmes are relatively well understood, the relationship between these benefits and their economic costs and savings has not been comprehensively studied. It is known that the economic burden of HIV infection is substantial [15]. A clear and objective assessment of the return on investment due to PMTCT programmes is an important input in the decision-making process for health planners and policymakers. Tasked with allocating limited resources, health planners and policymakers must make informed evaluations whether the further scale-up of PMTCT programmes will be a cost-effective means for averting paediatric HIV infections and whether it will make good use of prevention resources [16-19]. Therefore, we primarily aimed to evaluate PMTCT programmes province-wide at the macro level by retrospectively quantifying the return on investment about Yunnan province's PMTCT programmes over the 10 years from 2006 to 2015 . Second, we aimed to estimate the historical economic impacts of the programmes from a policymaker perspective.

\section{Methods}

The methodology we applied in the study was in accordance with the Consolidated Health Economic Evaluation Reporting Standards (CHEERS) statement guidelines [20].

\section{Study overview}

PMTCT services were provided by different maternal and infant healthcare centres at their respective administrative levels in Yunnan province. The target population of PMTCT programmes was pregnant women living with HIV (including those with infants less than 18 months old). PMTCT services were first piloted in Yunnan province in 2003. According to the regimens commented by the WHO, single-dose nevirapine was provided to HIV-infected pregnant women. In 2005, PMTCT programmes began to scale up and expand.
The regimens were changed to zidovudine with nevirapine for HIV-infected pregnant women starting from 14 weeks of gestation until delivery. Newborns were given 42 days of nevirapine with formula feeding, which helped to reduce the risk of HIV transmission from 34.80 to $11.36 \%$, approximately reduced by $2 / 3$. The PMTCT regimen changed again to a triple-drug regimen in 2008, which contained zidovudine, efavirenz and lopinavir/ritonavir. Since 2015, WHO Option B+ has been included in Yunnan PMTCT programmes, which will hopefully encourage Yunnan province to move towards achieving the elimination certification. Table 1 describes the services and interventions offered during the Yunnan PMTCT programmes' major development period.

A cost-effective analysis was conducted from the perspective of the health system, and a cost-benefit analysis was conducted from the perspective of policymakers.

Information on the investment in Yunnan's PMTCT programmes was obtained from the Yunnan AIDS Prevention Bureau. Annual investments from all sources over the time period from 2006 to 2015 were summed and used in further economic impact analyses. All investments in PMTCT strictly obeyed the regular use solely for PMTCT services. The basic costs incurred by this programme are fixed asset purchasing (including medical equipment and office equipment), ability building (including technical personnel training, supervisor and evaluation), interventions (including health education, inspector subsidizing, pregnant women screening, $\mathrm{CD} 4+$ testing, correct diagnosing of HIV-infected pregnant women, ART for HIV-infected pregnant women, early diagnosis of newborns, formula feeding, care and assistance for HIV-infected pregnant women in poor conditions and follow-up). All investments and costs from 2006 to 2015 were first estimated in 2016 Chinese Yuan (CN¥). They were then converted to 2016 United States Dollars (US\$) using the 23 November 2016 exchange rate $(\mathrm{CN} ¥ 6.8916=\mathrm{US} \$ 1.0000)$. The average inflation rate in China in the last 5 years ranged from 0.0 to $5.0 \%$ [21]. Based on the commendation from the World Health Organization CHOosing Interventions that are Cost-Effective (WHO-CHOICE), a discount rate of $3.0 \%$ was used to convert the economic costs and health outcomes in the baseline analysis [22]. A discount rate of 0.0 and $5.0 \%$ was used in the sensitivity analysis. The mother-to-child transmission (MTCT) rates used in the calculations of paediatric HIV infections averted were estimated using HIV surveillance data from the Yunnan Maternal and Infant Health Care Centre. Because the study was based on aggregate data, ethical approval was not required. All data used in this study were obtained through approvals from Yunnan AIDS Prevention Bureau. 
Table 1 Main activities/interventions of each stage's PMTCT programs in Yunnan Province, China

\begin{tabular}{|c|c|}
\hline Year & Activities/interventions \\
\hline 2003 & $\begin{array}{l}\text { 1. Voluntary counseling and testing }(\mathrm{VCT}) \text {. } \\
\text { 2. Safe delivery services. } \\
\text { 3. Feeding counseling services. } \\
\text { 4. HIV-antibody testing for infants with the age of } 12 \text { and } 18 \text { months old. }\end{array}$ \\
\hline 2004-2007 & $\begin{array}{l}\text { 1. Health education. } \\
\text { 2. Counselting and testing services. } \\
\text { 3. ARV or ART (CD4 }+T \text { cell }<250 \text {, starting ART, AZT }+3 T C+N V P ; C D 4+T \text { cell } \geq 250 \text {, } \\
\text { AZT + NVP before, during and after pregnancy or NVP after pregnancy). } \\
\text { 4. Safe delivery services (HIV positive not the only indication of the cesarean). } \\
\text { 5. Encourage formula feeding, avoid breast feeding and forbid mixed feeding. }\end{array}$ \\
\hline 2008-2010 & $\begin{array}{l}\text { 1. Counseling and testing services. } \\
\text { 2. Health care for pregnant women with HIV. } \\
\text { 3. ART (with no indication of ART or having not accepted ART before, before } \\
\text { paregnancy: AZT; during pregnancy: AZT + NVP + 3TC; after: AZT). } \\
\text { 4. Safe delivery services. } \\
\text { 5. Provide formula feeding, avoid breast feeding and forbid mixed feeding. } \\
\text { 6. Supply supporting and care services. }\end{array}$ \\
\hline 2011-2014 & $\begin{array}{l}\text { 1. Provide AIDS, Syphilis and Hepatitis B counseling and testing services (Opt-out). } \\
\text { 2. Select the pregnancy outcomes. } \\
\text { 3. Supply PMTCT services to pregnant women with HIV and their children (including ART, } \\
\text { (whatever CD4+ T cell counts, recommendation ART, AZT + 3TC + LPV/r or AZT + 3TC + EFV } \\
\text { Or CD4 + Tcell } \leq 350, \text { ART after pregnancy, CD4 + Tcell> } 350 \text {, stopping ART,) safe delivery services, } \\
\text { scientific feeding guiding and counseling (advocate formula feeding, avoid breast feeding } \\
\text { and forbid mixed feeding)). } \\
\text { 4. Supply AIDS early diagnosis for infants born to pregnant women with HIV/AIDS and supply } \\
\text { ARV to them to prevent opportunistic infection. }\end{array}$ \\
\hline 2015-Nowadays & $\begin{array}{l}\text { 1. Health education and health promotion. } \\
\text { 2. Active counseling and testing services (Opt-out). } \\
\text { 3. PMTCT services (including ATR (whatever CD4 + T cell counts, start ART at once after } \\
\text { infomed consent), safe delivery services, ARV for infants, cientific feeding guiding and } \\
\text { counseling (advocate formula feeding, avoid breast feeding and forbid mixed feeding)). } \\
\text { 4. Supply AIDS early diagnosis and HIV-antibody testing for infants born to pregnant women with HIV/AIDS. }\end{array}$ \\
\hline
\end{tabular}

\section{Outcome measures}

The outcomes of our study included paediatric HIV cases averted, quality of life years (QALY) acquired and economic costs avoided.

\section{Paediatric HIV cases averted}

We used the difference between the HIV MTCT rates in the pre-PMTCT era (mean rate from 2003 to 2005 in Yunnan counties with no pilot PMTCT services) and the post-PMTCT era (mean rate from 2006 to 2015 across all of Yunnan province after PMTCT services had been scaled up) to estimate the total number of paediatric HIV cases averted. The total estimated number of paediatric cases averted was compared to investments made over the same 10-year time period to generate an estimated cost per averted infection. Because the PMTCT interventions that we compared in the study were all carried out in Yunnan Province itself, we assumed a pre-PMTCT era with no other related programmes or very minimal programmes implemented for the prevention of mother-to-child transmission of HIV as the base for the comparison.

\section{QALY acquired}

The net number of QALY acquired by a single averted paediatric HIV infection was a function of the difference between the expected number of QALY of a child without HIV infection and the excepted number of QALY of a child with HIV infection [23]. We adopted the health utilities of 0.74 for the HIV sample [24] and of 1 for the general sample to weight the life years gained and the determined QALY acquired. Based on a previous study [25], we assumed the life expectancy of a treated HIV-infected child to be 28.79 years. Normal life expectancy for children born in Yunnan Province is 70.5 years [26]. The total estimated QALY acquired was compared to investments made over the same 10-year time period to generate an estimated cost per QALY gained.

\section{Economic costs avoided}

We calculated the total economic cost of a single paediatric HIV case as the sum of direct and indirect costs. Direct costs were defined as life-long expenses associated with HIV/AIDS treatment (mainly comprising the costs of regular testing and follow-up, ART, and the prevention, diagnosis, and treatment of opportunistic infections [27]). Direct costs were first estimated for adults 
and then adjusted for children by applying a multiplier of 1.75 [28]. Indirect costs were equated to the value of productivity lost due to early HIV/AIDS-related death and estimated in four steps. First, the age range during which members of society contribute to the labour force was assumed to be 18 to 60 [29]. Because the life expectancy of children with HIV/AIDS is 28.79 years [25], the effective labour years were assumed to be 10.79 years, and the potential labour years lost was estimated to be 31.21 years for a single paediatric HIV case. People living with HIV tend to experience unemployment; according to an international labour organization, the unemployment rate of HIV-infected persons was more than three times the unemployment rate of normal individuals in the country [30]. Based on previous studies [31, 32], we speculated that the unemployment rate of HIV-infected children when they grew to an effective labour force age was more than five times that in the country, which was $20.5 \%(4.1 \% * 5)$ [33]. Second, the present value of forgone lifetime earnings (E) was estimated by the human capital approach developed by Max and colleagues [34, 35]. A discount rate $\left(\mathrm{c}_{\text {discount }}\right)$ was used to convert a stream of earnings into its current worth. To consider the potential growth of future earnings, we assumed an annual productivity growth rate of $8.5 \%$, which is approximately the growth rate of the GDP per capita in Yunnan province in 2016 [36]. Third, we considered weighting the annual earnings using an income distribution coefficient $\left(\mathrm{c}_{\text {income }}\right)$ due to the differences in the different age groups [37]. The equation for lifetime forgone earnings (E) was as follows:

$$
\begin{aligned}
E_{H I V+} & =\sum_{Y=18}^{Y=28.79}\left[G D P\left(Y_{2015}\right) \times(1+0.085)^{Y-2015}\right. \\
& \left.\times c_{\text {income }}\right] /\left(1+c_{\text {discount }}\right)^{Y-2016} \\
E_{\text {normal }} & =\sum_{Y=18}^{Y=60}\left[G D P\left(Y_{2015}\right) \times(1+0.085)^{Y-2015}\right. \\
& \left.\times c_{\text {income }}\right] /\left(1+c_{\text {discount }}\right)^{Y-2016}
\end{aligned}
$$

We estimated the return-on-investment (ROI) as a ratio, with total savings (numerator) divided by the total investment (denominator) [37].

\section{Sensitivity analysis}

One-way sensitivity analysis was conducted to examine the impact of changes in model assumptions. First, we assessed the impact of changing the HIV MTCT rate in the pre-PMTCT era to its largest and smallest values (20\% 45\%) reported in the previous literature [1]. Second, we changed the growth rate of GDP per capita in Yunnan province to the lowest rate in China in the past ten years with $6.4 \%$ (2015) and to nearly the highest rate in China in the last ten years with $12.1 \%$ (2006) [38]. Third, we assessed the impact of changing life expectancy values to their upper (69.4years) [39] and lower limits (14.23 years) [40]. Fourth, we set the discount rate for converting investment and economic costs to its largest and smallest values at 0.0 and $5.0 \%$, respectively. Finally, we performed a two-way sensitivity analysis. All parameter values used in the analysis are presented in Table 2.

\section{Results}

Investment in PMTCT

The total investment over the 10-year study period as well as investment stratified by calendar year and investment sources (e.g., Chinese Central Government, International Aid) are presented in Table 3 . The total investment increased from US\$3.9 million in 2006 to US\$5.1 million in 2015 (a 38.5\% increase over 10 years).

\section{Savings generated by PMTCT}

Table 4 presents the estimated number of paediatric HIV infections averted by the PMTCT programmes in Yunnan Province from 2006 to 2015 as well as the investment required per infection averted. Overall, we estimated that approximately 2725 new infections were averted at an estimated US\$18,045 investment required per infection averted. Similarly, Table 4 also shows the QALY acquired and investment required per QALY acquired. Overall, a total of 134,078 QALY were acquired at an investment per QALY of US\$367.

Table 5 shows the direct, indirect, and total economic costs saved by PMTCT based on the estimated number of paediatric HIV infections averted. In total, we estimated that Yunnan's PMTCT programmes saved US $\$ 0.5$ billion to US $\$ 4.4$ billion in direct costs (i.e., treatment provided) and US $\$ 3.9$ billion in indirect costs (i.e., lost productivity). On average, we estimated that for every paediatric HIV infection averted, the healthcare system saved US $\$ 179,444$ in treatment costs and society gained US $\$ 1,433,310$ in productivity.

\section{Return on investment}

As shown in Table 5, we found that the ROI ratio was more than 45 every year during the study period, meaning that for every US\$1 invested in PMTCT in Yunnan province, more than US $\$ 45$ was saved by avoiding spending on treatment costs and loss of productivity. The total ROI ratio was 88.4 during the study period, meaning that for every US\$1 invested in PMTCT in Yunnan province during the study period, more than US $\$ 88.4$ were saved by avoiding spending on treatment costs and loss of productivity. 
Table 2 Parameters and ranges for analysis

\begin{tabular}{|c|c|c|c|c|}
\hline Variable & Base & low & high & source \\
\hline \multicolumn{5}{|l|}{ Mother-to-Child transmission rate (\%) } \\
\hline Pre-PMTCT era & 34.80 & 20.00 & 45.00 & surveillance data; [1] \\
\hline \multicolumn{5}{|l|}{ Pro-PMTCT era } \\
\hline 2006 & 8.78 & - & - & surveillance data \\
\hline 2007 & 11.36 & - & - & surveillance data \\
\hline 2008 & 6.73 & - & - & surveillance data \\
\hline 2009 & 8.62 & - & - & surveillance data \\
\hline 2010 & 6.49 & - & - & surveillance data \\
\hline 2011 & 4.47 & - & - & surveillance data \\
\hline 2012 & 4.36 & - & - & surveillance data \\
\hline 2013 & 4.19 & - & - & surveillance data \\
\hline 2014 & 3.16 & - & - & surveillance data \\
\hline 2015 & 3.13 & - & - & surveillance data \\
\hline \multicolumn{5}{|c|}{ Total number of HIV-infected pregnant women in the particular years } \\
\hline 2006 & 923 & & & surveillance data \\
\hline 2007 & 1043 & & & surveillance data \\
\hline 2008 & 1236 & & & surveillance data \\
\hline 2009 & 1702 & & & surveillance data \\
\hline 2010 & 1723 & & & surveillance data \\
\hline 2011 & 1867 & & & surveillance data \\
\hline 2012 & 1940 & & & surveillance data \\
\hline 2013 & 1904 & & & surveillance data \\
\hline 2014 & 2045 & & & surveillance data \\
\hline 2015 & 2011 & & & surveillance data \\
\hline $2006-2015$ & 16,394 & & & surveillance data \\
\hline \multicolumn{5}{|l|}{ Health Utility } \\
\hline General population & 1.00 & - & - & \\
\hline Patient with HIV & 0.74 & - & - & [24] \\
\hline Average life expantancy (Yunnan Province, 2015) & 70.50 & - & - & [26] \\
\hline Cost(2016,US\$) & & & & [27] \\
\hline ART per person per year & 2947.94 & - & - & \\
\hline Regular follow-up and testing per person per year & 94.46 & - & - & \\
\hline Uptoward effect treatment per person per year & 287.74 & - & - & \\
\hline Opportunistic infection per person per year & 231.30 & - & - & \\
\hline Total direct cost per year per person & 3561.44 & - & - & \\
\hline Coefficient for direct cost of infant:adult & $1.75: 1$ & & & \\
\hline Total direct cost per year per infant & 6232.51 & - & - & \\
\hline Life expentancy of newborn of HIV with treatment & 28.79 & 14.23 & 69.40 & {$[25,39,40]$} \\
\hline Coefficient for unemployment rate of HIV positive:general & $5: 1$ & & & [30-32] \\
\hline Average unemployment rate in China & $4.10 \%$ & & & [33] \\
\hline GDP per capita in 2015 (\$US) & 4222.66 & - & - & [36] \\
\hline Annual rate of growth of GDP per capita & $8.50 \%$ & $6.50 \%$ & $12.10 \%$ & {$[36,38]$} \\
\hline Discount rate & $3.00 \%$ & $0.00 \%$ & $5.00 \%$ & {$[22,23]$} \\
\hline
\end{tabular}


Table 3 The investments per year from 2006 to 2015 (US\$, 2016)

\begin{tabular}{llllll}
\hline year & Chinese Central Government & Local Administration & International Aid & Social Finacing & Total Investment \\
\hline 2006 & $3,674,879$ & 162,323 & 94,266 & 0 & $3,931,468$ \\
2007 & $3,599,579$ & 260,445 & 124,372 & 4353 & $3,988,749$ \\
2008 & $2,811,680$ & 294,274 & 140,639 & 4353 & $3,250,946$ \\
2009 & $2,979,986$ & 417,998 & 132,723 & 726,258 & $4,256,965$ \\
2010 & $4,928,218$ & 470,442 & 77,174 & 653,137 & $6,128,971$ \\
2011 & $5,561,483$ & 288,188 & 6843 & 0 & $5,856,514$ \\
2012 & $5,514,498$ & 189,945 & 6419 & 0 & $5,710,862$ \\
2013 & $4,879,138$ & 197,393 & 5242 & 10,065 & $5,091,838$ \\
2014 & $5,293,116$ & 187,487 & 0 & 18,730 & $5,499,333$ \\
2015 & $5,085,509$ & 218,356 & 0 & 155,129 & $5,458,994$ \\
$2006-2015$ & $44,328,086$ & $2,686,851$ & 587,678 & $1,572,025$ & $49,174,640$ \\
\hline
\end{tabular}

\section{Sensitivity analysis}

When we increased the HIV MTCT rate during the pre-PMTCT period from 34.8 to $45.0 \%$, the investment per paediatric HIV infection averted declined from US $\$ 18,045$ to US\$13,370. The investment per QALY acquired also declined from US\$367 to US\$272. In contrast, the ROI ratio increased from 88.4 to 119.3 . When we increased the discount rate from 3.0 to $5.0 \%$, the investment per paediatric HIV infection averted increased from US $\$ 18,045$ to US $\$ 19,935$, the investment per QALY acquired increased from US $\$ 367$ to US $\$ 405$, and the ROI ratio declined from 88.4 to 52.5 . When we increased the life expectancy from 28.79 years to 69.4 years, the investment per QALY acquired increased from US\$367 to US\$943, and the ROI ratio decreased from 88.4 to 40.7 . Lastly, by changing the GDP growth rate in Yunnan province from 8.5 to $12.1 \%$, making it the second highest growth rate in China in the last ten years, the ROI ratio increased from 88.4 to 369.9 (Figs. 1, 2, 3). As shown in Table 6, when we changed the two assumptions simultaneously, the investment required per paediatric HIV infection averted varied from US $\$ 11,530$ to US\$40,461, the investment per QALY acquired varied from US\$223 to US\$1913, and the ROI ratio varied from 19.3 to 1708.6 .

\section{Discussion}

We found that the US\$49.17 million investment in Yunnan's PMTCT programmes over the period from 2006 to 2015 averted an estimated 2725 new paediatric HIV infections and resulted in an estimated 134,008 QALY acquired. It furthermore saved an estimated US $\$ 0.5$ billion in treatment expenditures for Yunnan's healthcare system and nearly US\$4 billion in productivity. On a per case basis, we estimated that for every US $\$ 18,005$ invested, one paediatric HIV infection could be avoided, which meant that an estimated US\$0.2 million in healthcare costs and US\$1.4 million in lost productivity would be saved. On a per QALY basis, we estimated that for every US\$367 invested, one QALY was gained.

Table 4 Savings of PMTCT (US\$, 2016)

\begin{tabular}{|c|c|c|c|c|}
\hline year & $\begin{array}{l}\text { Number of pediatric } \\
\text { HIV infections averted }\end{array}$ & $\begin{array}{l}\text { Investment per pediatric } \\
\text { HIV infections averted }\end{array}$ & Total QALYs acquired & $\begin{array}{l}\text { Investment per } \\
\text { QALY acquired }\end{array}$ \\
\hline 2006 & 144 & 27,387 & 7063 & 557 \\
\hline 2007 & 148 & 26,883 & 7301 & 546 \\
\hline 2008 & 209 & 15,588 & 10,261 & 317 \\
\hline 2009 & 246 & 17,335 & 10,282 & 352 \\
\hline 2010 & 280 & 21,890 & 13,775 & 445 \\
\hline 2011 & 312 & 18,765 & 15,355 & 381 \\
\hline 2012 & 325 & 17,550 & 16,010 & 357 \\
\hline 2013 & 336 & 15,136 & 16,551 & 308 \\
\hline 2014 & 367 & 14,984 & 18,056 & 305 \\
\hline 2015 & 358 & 15,241 & 17,623 & 310 \\
\hline $2006-2015$ & 2725 & 18,045 & 134,078 & 367 \\
\hline
\end{tabular}


Table 5 Savings of PMTCT (US\$, 2016)

\begin{tabular}{lllllll}
\hline Year & Direct costs saved & Indirect costs saved & Total costs saved & ROl of direct benefit & ROl of indirect benefit & ROI of total benefit \\
\hline 2006 & $25,757,745$ & $154,660,310$ & $180,418,055$ & 5.6 & 38.3 & 44.9 \\
2007 & $26,623,550$ & $168,395,173$ & $195,018,723$ & 5.7 & 41.2 & 47.9 \\
2008 & $37,422,765$ & $249,340,014$ & $286,762,779$ & 10.5 & 75.7 & 87.2 \\
2009 & $44,063,311$ & $309,261,465$ & $353,324,777$ & 9.4 & 71.7 & 82.0 \\
2010 & $50,238,980$ & $371,434,400$ & $421,673,380$ & 7.2 & 59.6 & 67.8 \\
2011 & $56,000,568$ & $436,140,570$ & $492,141,138$ & 8.6 & 73.5 & 83.0 \\
2012 & $58,388,457$ & $479,019,957$ & $537,408,415$ & 9.2 & 82.9 & 93.1 \\
2013 & $60,362,285$ & $521,655,858$ & $582,018,142$ & 10.9 & 101.5 & 113.3 \\
2014 & $65,856,571$ & $599,527,566$ & $665,384,137$ & 11.0 & 108.0 & 111.9 \\
2015 & $64,271,038$ & $616,335,350$ & $680,606,389$ & 10.8 & 78.4 & 123.7 \\
$2006-2015$ & $488,985,271$ & $3,905,770,664$ & $4,394,755,935$ & 8.9 & 88.4
\end{tabular}

Considering the most significant route of HIV infection among children in developing countries [41] and the rapid transmission of HIV between the two generations is MTCT, it was therefore urgent to implement PMTCT programmes for pregnant women living with HIV and their newborns. Based on the economic and development situations, putting available PMTCT resources to optimal use is essential. From 2006 to 2015 in Yunnan province, nearly US $\$ 50$ million was invested in PMTCT programmes. After 2010, an annual investment of more than US\$5 million averted more than 300 paediatrics HIV infections per year. Given the investment per paediatric HIV infection averted and the investment per QALY acquired in 2013, 2014 and 2015, this is considerably lower than was made available for PMTCT in previous years, suggesting that PMTCT programmes were more cost-effective in this period. In this period, the ART regimens changed to a triple therapy. The national-provincial-city level-county-level network has maturely developed. The capacity of the organizations to implement, manage and monitor the PMTCT programmes has greatly advanced. This finding is consistent with an empirical evaluation of PMTCT programmes in Zambia in 2014, which also demonstrated the cost-effectiveness of PMTCT programmes [42].

Our study also suggested that Yunnan's PMTCT programmes saved US $\$ 4.4$ billion - US $\$ 0.5$ billion in direct costs and US $\$ 3.9$ billion in indirect costs in ten years based on the cost-benefit analysis. From a financial perspective, this study demonstrated that the investment in PMTCT programmes made good financial sense. The ROI was 88.4, meaning that every US\$1 invested brought about US $\$ 88.4$ in benefits, which was more than some previous studies' results about ROI, such as
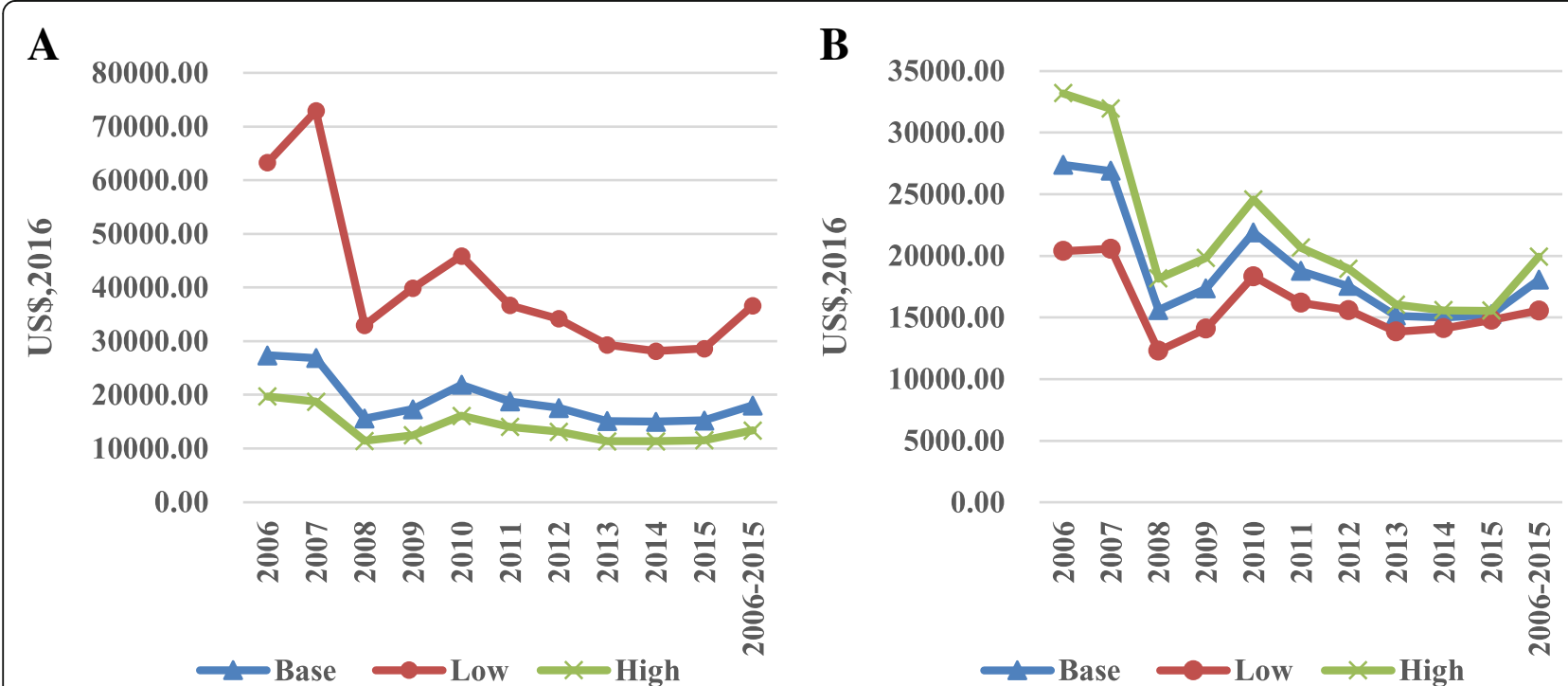

Fig. 1 a the sensitivity analysis of investment per pediatric HIV infection averted by changing HIV MTCT rate in the pre-PMTCT period. $\mathbf{b}$ the sensitivity analysis of investment per pediatric HIV infection averted by changing discount rate 


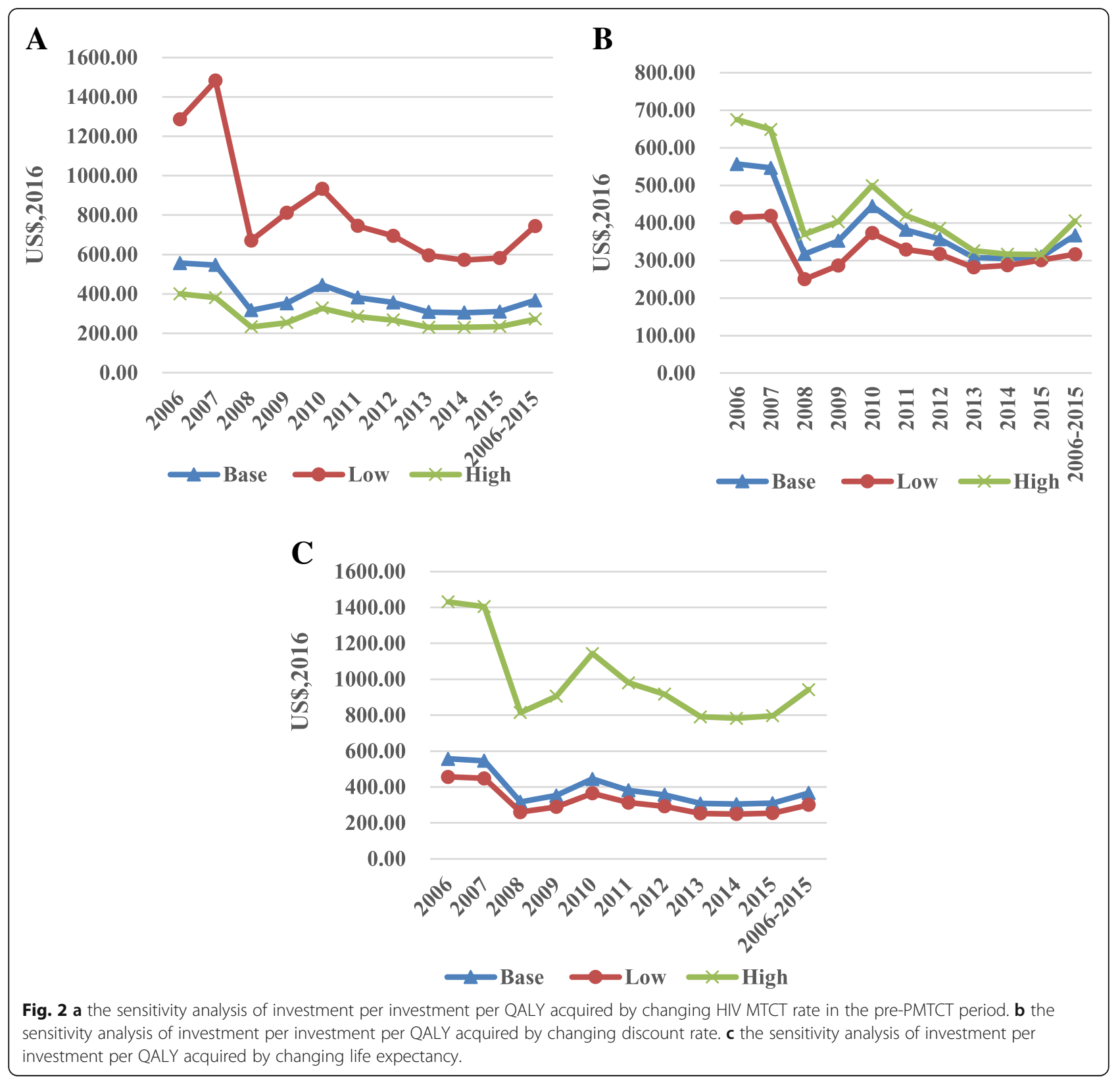

1.0 40.0 in the other HIV/AIDS programmes [43-45]. In other words, the generated benefits of the investment in PMTCT programmes were greater than the investments, and we could consider the investments in PMTCT programmes to be cost-efficient. In particular, the cost-efficiency was more noticeable in recent years (more than US $\$ 0.6$ billion was saved).

Given the robustness of our cost-effective measures after examining their sensitivity after changing a variety of parameters, including the HIV MTCT rate in the pre-PMTCT period, discount rate, life expectancy of HIV-infected infants and the GDP growth rate of Yunnan province, we consider this cost efficiency of the PMTCT programmes to be credible. We also found that the investment per QALY acquired increased with the increased life expectancy of people living with HIV due to lifelong ART. This means that PMTCT programmes in the ART period could require more investment. Because of the rapid growth of economics in China and based on economic development in Yunnan province, we supposed a high GDP growth rate of more than 10\%, which approaches the highest growth rate in China in the last 10 years [38]. In this case, the benefits of the investment in PMTCT programmes increased greatly. If we successfully avert one newborn from being infected with HIV, a healthy child will yield more productivity to society when he or she grows to the age with effective labour force under this development situation. The 


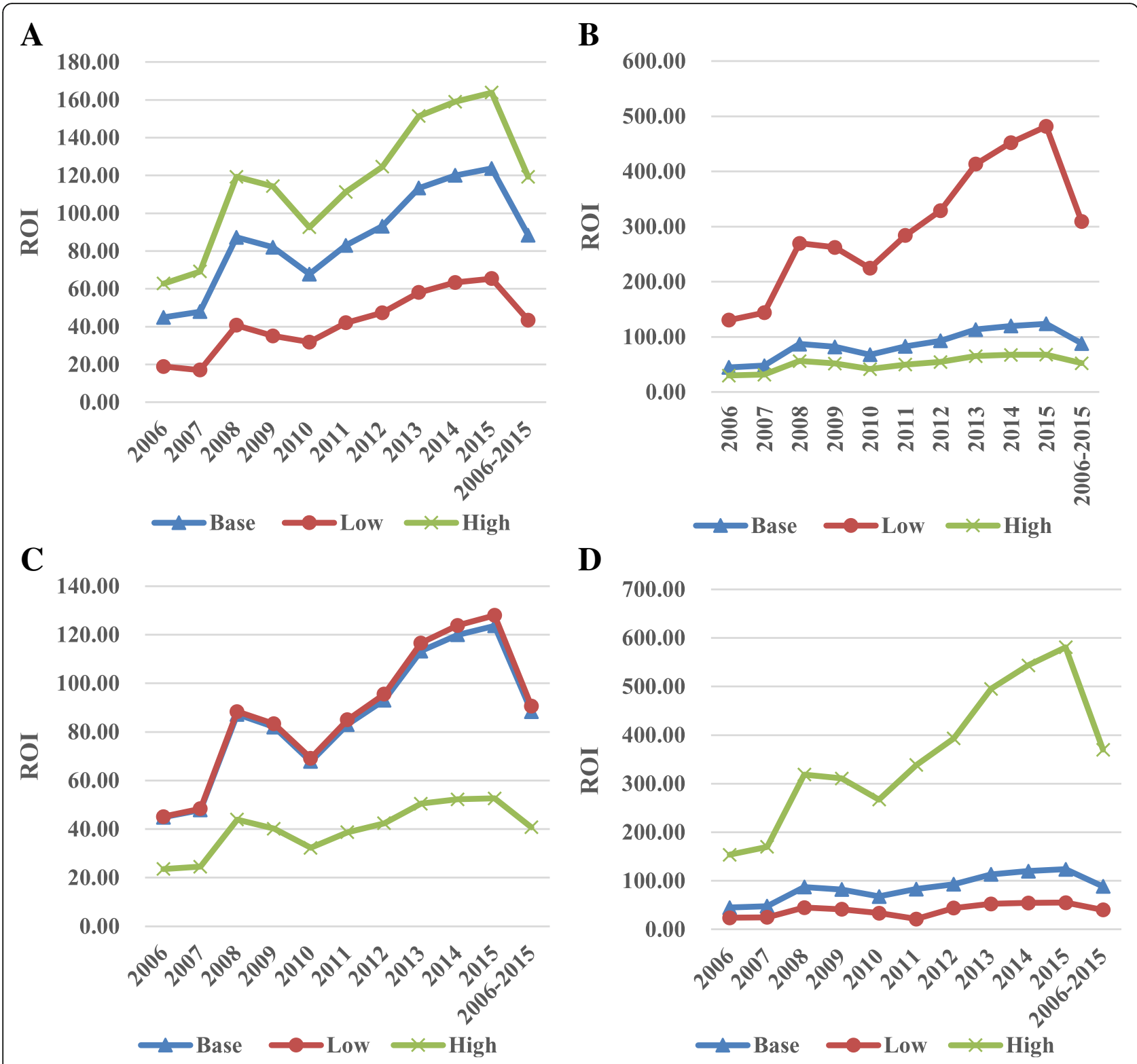

Fig. 3 a the sensitivity analysis of ROI by changing HIV MTCT rate in the pre-PMTCT period. $\mathbf{b}$ the sensitivity analysis of ROI by changing discount rate. c the sensitivity analysis of ROI by changing life expectancy. $\mathbf{d}$ the sensitivity analysis of ROI by changing growth rate of GDP in Yunnan province

optimization results supported the ongoing investments in effective PMTCT programmes in the future.

Cost-effectiveness and cost-benefit analysis above could provide meaningful information about the economic value of PMTCT strategies and enable optimal allocative efficiency analyses to highlight the gains that have been

Table 6 The muiti-way sensitivity analysis (US\$, 2016)

\begin{tabular}{llll}
\hline & $\begin{array}{l}\text { Investment per pediatric } \\
\text { HIV infections averted }\end{array}$ & $\begin{array}{l}\text { Investment per } \\
\text { QALYs acquired }\end{array}$ & ROI \\
\hline Min value & 11,530 & 223 & 19.3 \\
Max value & 40,461 & 1913 & 1708.6 \\
\hline
\end{tabular}

achieved by targeting the constrained resources to the right interventions. The investment in PMTCT programmes would not only generate benefits for the children but also for the mothers, which could help detect undiagnosed infections and allow mothers living with HIV to receive life-saving ART immediately. If this benefit was to be included, the final results would be more positive.

From 2006 to 2015, PMTCT programmes have been scaled up and extended in Yunnan province, and the rate of mother-to-child transmission has decreased substantially. Currently, as the first country in the world to declare "triple elimination certifications", China is on the road to eliminate the transmission of HIV, hepatitis B 
and syphilis from mother-to-child. Importantly, Yunnan province began to initiate this work. We aim to eliminate the transmission of HIV from mother-to-child during the 13th five-year plan (from 2016 to 2020) [46]. Therefore, investing in PMTCT programmes and advancing the use of investments will build a brighter future for children, mothers, provinces and the nation.

Our study had several limitations. First, we conducted an economic evaluation on the macro-level and an ecological study using aggregate-level data. The ecological evaluation did not identify the heterogeneity among individuals and could not control the confounding factors. Second, we used the investment as the cost to do the analysis; although all the expenditures on the PMTCT programmes were earmarked funding for their specific purposes alone, it could over-estimate the net cost. Third, no study has reported the life expectancy of HIV-infected children in China. We used the life expectancy of HIV-infected children in Africa reported in the published study to substitute for this finding. Some differences may exist among different countries regarding the life expectancy of HIV-infected children. Fourth, our study did not consider the influence of other HIV/AIDS prevention programmes. Finally, we used QALY acquired in the investment-utility analysis, but using QALY to estimate the utility is sometimes subjective. Finally, the loss of productivity may be overestimated based on the PMTCT programmes because some other HIV prevention programmes may exist over the lifetime. Despite these limitations, we believe that our study thoroughly quantified the historical economic value of the PMTCT programmes carried out in Yunnan province based on the perspective of a policymaker and showed the cost-effective and cost-benefit of the PMTCT programmes from 2006 to 2015. We believe that our study used the scientific method to verify the PMTCT programmes' provisions from an economic point of view to help make the resource allocation strategy more evidence-based.

\section{Conclusion}

Our results support the ongoing investment in PMTCT programmes in Yunnan Province. PMTCT strategies were a cost-effective and cost-benefit strategy from 2006 to 2015. Despite requiring higher investments in the future, the overall investment in PMTCT programmes in Yunnan province could be offset by averting more paediatric infections. When we achieve the goal of eliminating the transmission of HIV from mother-to-child during the 13th five-year plan, investing in PMTCT programmes and advancing the efficiency of the investments using will build a brighter future for children, mothers, provinces and the nation.

\section{Abbreviations}

CHEERS: Consolidated health economic evaluation reporting standards: MTCT: Mother-to-child transmission; PMTCT: Prevention of mother-to-child transmission; QALY: Quality of life years; ROI: Return-on-investment ratio; WHO-CHOICE: World Health Organization CHOosing Interventions that are Cost-Effective

\section{Acknowledgements}

The authors would like to thank Dr. Zheng Jisheng and Dr. Du Ning from Yunnan AIDS Bureau doing the data collection and verifying. We thank Dr. Wu Zunyou from National Center for STD Control, Chinese Centers for Disease Control and Prevention help us doing the study design and develop the manuscript.We thank Dr. Jennifer McGoogan doing the English writing adjustment and giving us many professional comments about the manuscript writing. We thank all the professional staff members who devote themselves to PMTCT in Yunnan Province.

\section{Funding}

This work was supported by Innovation Group Project of AIDS research in Yunnan Province(grant number: 2014HC019) and Doctoral Innovation and Science Foundation of Kunming Medical University (grant number:

2017B001). The funding organizations had no role in the development of study design, collection, analysis, and interpretation of data, the writing of the report, or the final decision to submit the manuscript for publication.

\section{Availability of data and materials}

The full database is available from the corresponding author on reasonable request.

\section{Disclaimer}

The views and opinions expressed herein belong to the authors alone, and do not represent the official policy, or endorsement of their affiliated institutions.

\section{Authors' contributions}

GGP and WXW designed the study. WXW and ZJR performed the statistical analysis. WXW and GGP interpreted the results and developed the initial manuscript draft. LL supervised the study. All authors contributed to manuscript revisions and approved the final version for publication. LL had full access to all the data and had final responsibility for the decision to submit for publication.

\section{Ethics approval and consent to participate}

Because the study was based on aggregate data, ethical approval was not required. All data used in this study were obtained through approvals from Yunnan AIDS Prevention Bureau.

Consent for publication

Not applicable.

Competing interests

The authors declared that they have no competing interests.

\section{Publisher's Note}

Springer Nature remains neutral with regard to jurisdictional claims in published maps and institutional affiliations.

\section{Author details}

${ }^{1}$ Yunnan Center for Disease Control and Prevention, No.158, Dongsi Street, Xishan District, Kunming 650022, Yunnan Province, China. 'Department of Public Health, Kunming Medical University, No. 1168, West Chunrong Road, Yuhua Street, Chenggong District, Kunming 650599, Yunnan Province, China. ${ }^{3}$ Yunnan Maternal and Child Health Care hospital, No. 200, Gulou Road, Wuhua District, Kunming 650032, Yunnan Province, China. ${ }^{4}$ Health and Family Planning Commission of Yunnan Province, No. 309, Guomao Street, Kunming 650299, Yunnan Province, China. 
Received: 17 November 2017 Accepted: 10 January 2019 Published online: 17 January 2019

\section{References}

1. Li Y. The process of prevention of mother-to-child transmission of AIDS. Journal of Kunming Medical University. 2012;11:1-3.

2. Dai R, Feng J, Tang MZ, et al. Mother-to-child transmission rate of HIV and use of drugs to prevent the transmission in China: a systematic reviewer. Acad J Second Mil Univ. 2014;35:1094-102.

3. www.gov.cn. Yunnan: the epidemic of HIV was totally stable in Yunnan Province in 2016. http://www.gov.cn/xinwen/2016-11/30/content_5140127. htm. 2016-11-30/2016-12-28.

4. Yunnan Provincial Bureau of Statistics. The Statistical Yearbook of Yunnan Province in 2017. http://www.stats.yn.gov.cn/tjsj/tjnj/201810/t20181030_ 809120.htm.2018-10-30/2018-12-15.

5. Zhu XX, Wang XT. The analysis of experimental works in prevention mother-to-child transmission of HIV in Yunnan Province. Maternal \& Child Health Care of China. 2005;12:1430-1.

6. Xiong $\mathrm{YH}$, Liu DH, Yang $\mathrm{L}$, et al. The effectiveness analysis of prevention mother-to-child transmission of HIV in Honghe municipal, 2005-2007. Maternal \& Child Health Care of China. 2010;15:2097-100

7. Li QY, Zhu YH, Chen $\mathrm{MH}$, et al. The next step programs exploring and effectivess analysis of prevention mother-to-child transmission of HIV in Qujing municipal, 2005-2009. Sichuan Medical Journal. 2010;5:686-7.

8. Hong Y, Yang L, Gong CY, et al. The improvement stragety and utilizing prevention mother-to-child transmission of HIV service in Yunxi municipal. Maternal \& Child Health Care of China 2009. 33:4647-9.

9. Liu CX. The effectiveness analysis of prevention mother-to-child transmission of HIV in Chuxiong municipal, 2006-2010. Soft Science of Health. 2012;3:179-80.

10. Mao XMi, Wang Q, Yang HJ. Analysis on successful comprehensive intervention and effects which promote the prevention of AIDS from mother to infant. Modern Preventive Medicine. 2012:18:4716-8.

11. Wang W, Li C, Zhao FQ, et al. The analysis of prevention mother-to-child transmission of HIV in Honghe municipal, 2008-2010. Basical Level Medicine Forum. 2013;19:2563-4.

12. Zhan HL, Chi KF, He ZQ, et al. The effectiveness and trend of prevention mother-to-child transmission of HIV in Lijiang municipal, 2008-2013. Maternal \& Child Health Care of China. 2014:21:3377-9.

13. Shan D, Wang J, Sun JP, et al. A study on effectiveness of prevention of mother-to-child transmission among pregnant women in Dehong prefecture, Yunnan province, China from 2011 to 2013. Chin J Prev Med. 2014;11:942-6.

14. Li YX, Zhang XD. The retrospective analysis of prevention mother-to-child transmission in HIV-positive pregnant women in Chuxiong county, 2011-2013. Soft Science of Health. 2015;3:179-82.

15. Stephanie KY, David R, Bacon J, et al. Economic ecaluation of communitybased HIV prevention programs in Ontario: evidence of effectiveness in reducing HIV infections and health care costs. AIDS Behav2016;20: 1143-1156.

16. Söderlund N, Zwi K, Kinghorn A, et al. Prevention of vertical transmission of HIV: analysis of cost effectiveness of options available in South Africa. BMJ. 1999:318:1650-6.

17. Teerawattananon $Y$, Vos T, Tangcharoensathien $V$, et al. Cost-effectiveness of models for prevention of vertical HIV transmission-voluntary counseling and testing and choices of drug regimen. Cost Effectiveness and Resource Allocation. 2005:3:7.

18. Johri M, AkoArrey D. The cost-effectiveness of preventing mother-to-child transmission of HIV in low- and middle-income countries: systematic review. Cost Effectiveness and Resource Allocation. 2011;9:3.

19. Edusei $K O$, Guo YT, Thomas $L$, et al. Cost-effectiveness of integrated routing offering of renatal HIV and syphilis screening in China. Sexually Transmitted Disease. 2014;41:103-10.

20. Husereau D, Drummond M, Petrou S, et al. Consolidated health economic evaluation reporting standards(CHEERS) statement. Value Health. 2013;16:e1-5.

21. Trading Economics. China inflation. https://zh.tradingeconomics.com/china/ inflation-cpi. 2017-11-01.

22. World Health Organization. Making Choices in Health : WHO Guide to CostEffectiveness Analysis. https://www.who.int/choice/order form WHO_Guide pdf?ua $=1.2003 / 2016-12-28$
23. Drummond MF. Methods for the economice evaluation of health care programmes. Li Shixue. Beijing. In: China: People's medical publishing house; 2008 .

24. Miners A, Philips A, Kreif N, et al. Health-related quality-of-life of people with HIV in the era of combination antiretroviral treatment: a cross-sectional comparison with the general population. Lancet HIV. 2014;1:32-40.

25. Ciaranello AL, Doherty $K$, Penazzato $M$, et al. Cost-effectiveness of first-line antiretroviral therapy for HIV-infected African children less than 3 years of age. AIDS. 2015;29:1247-59.

26. People.cn. The life expectancy of Yunnan province has increased 3.5 years in 5 years. http://yn.people.com.cn/news/yunnan/n2/2015/1231/c22849627438466.html.2015-12-31/2016-11-28.

27. Guo ZW. The direct medical costs analysis of natioanl free antiretroviral treatment for HIV/AIDS patients. Beijing: Chinese academy of medical sciences\&Peking union medical college; 2008

28. Custer B, Agapova M, Martinez RH. The cost-effectiveness of pathogen reduction technology as assessed using a multiple risk reduction model. Transfusion. 2010;50:2461-73.

29. Fang JQ. Health Statisics. Beijing: People's Medical Publishing House; 2006.

30. People.cn. The number of people living with HIV to accept ART therapy has set a new record, difficulties still exist to advance the AIDS prevention and therapy in the world. http://he.people.com.cn/n/2014/1202/c19223523080355.html. 2014-12-02/2017-11-01.

31. Legarth $\mathrm{R}$, Omland LH, Kronborg G, et al. Employment status in persons with and without HIV infection in Denmark: 1996-2011. AIDS. 2014;28:1489-98.

32. McGoldrick C. HIV and employment. Occup Med. 2012:62:242-53.

33. Trading Economics. China unemployment rate. https://zh.tradingeconomics. com/china/unemployment-rate. 2017-11-01.

34. Max W, Rice DP, Sung HY, et al. The economic burdern of smoking in California. Tob Control. 2004;13:264-7.

35. Max W, Rice DP, Sung HY, et al. Valuing human life: estimating the present value of lifetime earning. University of California; San Francisco: Institute for health \& aging http://escholarship.org/uc/item/82d0550k. 2004-1001/2016-11-28.

36. Yunnan Bureau of Statistics. Economic and Social Development Report of Yunnan Province in 2015. http://www.stats.yn.gov.cn/tjsj/tjgb/201604/ t20160418 675140.html.2016-04-18/2016-11-28.

37. Yang W. Study on personal education cost-benefit of undergreduate from rural areas. Shangxi: Northwest A\&F University; 2007

38. National Bureau of Statistics of the People's Republic of China. http://data. stats.gov.cn/search.htm?s=GDP.2017-11-01.

39. II. Demographic impact of AIDS. http://www.doc88.com/p-331480641388. html.2017-11-02.

40. Kuznik A, Lamorde M, Hermans S, et al. Evaluating of the cost-effectiveness of combination antiretroviral therapy for the prevention of mother-to-child transmission of HIV in Uganda. Bull World Health Organ. 2012;90:595-603.

41. Joshi S, Kulkarni V, Gangakhedkar R, et al. Cost-effectiveness of a repeat HIV test in pregnancy in India. BMJ Open. 2015:5:e006718.

42. Shattock AJ, Kerr CC, Stuart RM, et al. In the interests of time: improving HIV allocation efficiency modelling via optimal time-varying allocations. J Int AIDS Soc. 2016;19:20627.

43. Kivela J. Cost-benefit analysis of HIV prevention programs for Filipino Seafarers 2010-2015. http://www2.ilo.org/wcmsp5/groups/public/\%2D\%2Dasia/\%2D\%2D-ro-bangkok/\%2D\%2D-ilo-manila/documents/publication/ wcms 140905.pdf. 2017-11-02.

44. Lavadenz F, Pantanali C, Zeballos E. Thirty years of the HIV/AIDS epidemic in Argentina. Washington, DC: World Bank Group; 2015.

45. Brent RJ, A cost-benefit analysis of Female Primary Education as a means of reducing HIV/AIDS in Tanzania. http://www.retc.fordham.edu/images/ undergraduate/economics/faculty/brent/reducing_hiv-aids_in_tanzania.pdf. 2017-11-02.

46. People's Government of Yunnan Province.The plan of the Public Health of Yunnan province during the period of 13th Five years. http://www.yn.gov. cn/yn_zwlanmu/qy/wj/yzf/201710/P020171027619636258988.pdf. 2017-1027/2017-11-01. 